\title{
Drain or no drain in Rhomboid excision and Limberg rotational flap for pilonidal sinus
} Joshi $A,{ }^{1}$ D ${ }_{\text {Acharya } B^{2}}$ iD

${ }^{1}$ Arbin Joshi, Consultant Surgeon, B and B Hospital, Gwarko, Lalitpur, Nepal; ${ }^{2}$ Bigyan Acharya, FCPS resident, Kathmandu Model Hospital, Red Cross Marga, Kathmandu, Nepal.

\begin{abstract}
Background: Healing in Rhomboid flap for pilonidal sinus is always a problem. Different measures are applied to reduce the rate of wound infection with variable results.

Objectives: To determine the effect of routine use of drain on the rate of early wound complications and additional interventions after Rhomboid flap.

Methods: A retrospective chart review of all cases that underwent Rhomboid flap in five years at two tertiary care centres was done. Complication rates such as wound infection, wound disruption, and flap necrosis were evaluated.

Results: A total of 38 cases of Rhomboid flap are included for analysis. Out of all cases, 37 cases were done for Pilonidal sinus and one case for presacral dermoid cyst. In the first eight cases, flap was made without drain and subsequent 30 cases were done with two suction drains for five days. The rate of superficial wound infection in the group without drain was found to be significantly higher compared with flap with drain five (in eight) versus two (in 30$)(62.5 \%$ versus $6.66 \%, p<0.5)$. Conclusion: Drain placement after Rhomboid flap is a good intervention to reduce wound infection.
\end{abstract}

Key words: Pilonidal sinus; Rhomboid flap; Wound infection.

\section{INTRODUCTION}

$\mathrm{R}$ homboid excision of pathology such as pilonidal sinus and reconstruction with Limberg rotational flap is one of the most widely used procedures for any condition in the sacrococcygeal region. Delayed healing and wound infection are one of the major problems faced in any surgery in this region. Different methods are applied to reduce the rate of complications with variable results.

\section{Access this article online}

Website: www.jkmc.com.np

DOI: https://doi.org/10.3126/jkmc.v10i2.40018

\section{HOW TO CITE}

Joshi A, Acharya B. Drain or no drain in Rhomboid excision and Limberg rotational flap for pilonidal sinus. J Kathmandu Med Coll. $2021 ; 10(2): 80-3$.

\section{Address for correspondence \\ Dr. Arbin Josh \\ Consultant Surgeon, B and B Hospital, \\ Gwarko, Lalitpur, Nepal. \\ E-mail: joshiarbin2012@gmail.com}

Copyright ๔ 2021 Journal of Kathmandu Medical College (JKMC)

ISSN: 2019-1785 (Print), 2091-1793 (Online)
The rationale for routine use of drain in Rhomboid flap is not established. This study was conducted to determine whether routine use of drain affects the rate of early wound complications and additional interventions after Rhomboid flap.

\section{METHODOLOGY}

This is a retrospective observational study. This study (retrospective chart review) was conducted at two tertiary care centres from the period of June 2015 to May 2020 following the ethical principles of the Declaration of Helsinki. All consecutive cases of the pilonidal sinus with no active infection or discharge, irrespective of previous intervention with incision and drainage, and who underwent Rhomboid excision and Limberg flap reconstruction by a single surgeon (first author) were included in the study. Cases with active infection with ongoing pus discharge, American Society of Anaesthesiology (ASA) grade III and above, immunocompromised patients like patients with diabetes, on steroids or immunosuppressants, and patients who had undergone any other procedures in the sacrococcygeal region other than incision and drainage were excluded from the study. 
All patients were administered intravenous Ceftriaxone and Metronidazole preoperatively. All patients were operated in a prone Jackknife position under spinal anaesthesia. Measurement and marking were done with sinus opening in centre and breath of the rhomboid being $60 \%$ of its length so that a perfect rhomboid with two angles of 60 degrees and two angles with 120 degrees was made. Sinus track along with the marked rhomboid tissue was excised en bloc. The Limberg Rotational flap was created from the patient's adjacent right gluteal region to fill up the defect, sutured in two layers with polyglycolic acid 2:0 suture and skin sutured with nylon.

Drain placement was an optional procedure. In patients with drain, two suction closed drain 12 French was placed from both sides of the wound. Patients with drain were discharged with the drain to follow-up on post-operative day five (for removal of drain) and all patients were followed up on $14^{\text {th }}$ post-operative day for suture removal. Oral antibiotics were continued until the seventh post-operative day in all cases and according to sensitivity patterns in case of wound infection and culture showing growth of some organism. In case of off-midline opening of the sinus, modified Rhomboid excision done with rhomboid tilted away from the midline to accommodate all the openings.

\section{Table 1: Demographics of patients included in the study}

\begin{tabular}{lc}
\hline Description & Number/Ratio \\
\hline Total number of cases & 38 \\
Pilonidal sinus & 37 \\
Sacrococcygealdermoid & 1 \\
\hline Mean age of the patient ( \pm SD) & 32.57 ( $\mathbf{7 . 9 9 )}$ \\
\hline Gender ratio (M:F) & $32: 6$ \\
\hline Number of excluded cases & 2 (Diabetic) \\
\hline Average days of hospital admission (in days) & 2.7 \\
\hline Midline opening: Off midline opening ( $\mathrm{n}=37)$ & $29: 8$ \\
\hline Drain placed: Drain not placed $(\mathrm{n}=38)$ & $30: 8$ \\
\hline
\end{tabular}

All patients were advised not to soak the wound till the $14^{\text {th }}$ postoperative day and to avoid supine position while lying down till the seventh postoperative day. No dietary advice was given for the purpose of the operation. The dressing was done on the fifth postoperative day at the time of drain removal and on the $14^{\text {th }}$ postoperative day during suture removal. Any complications during both visits were recorded.

\section{RESULTS}

Thirty-eight consecutive cases of Rhomboid excision and Limberg flap in the sacrococcygeal region were included (Two cases out of forty total cases were excluded as those patients had diabetes). All except one case had indication for pilonidal sinus. One case of sacrococcygeal dermoid was also included. Out of 37 cases of pilonidal sinus, the majority of cases had opening at the midline. Only eight cases had off midline opening for which modified Limberg flap was done. In the first eight cases, Limberg Rotational Flap was done without a drain but in all later thirty cases, the drain was placed routinely irrespective of the size of the defect.

Superficial wound infection was found to be higher in patients in which drain was not used (5 in 8,62.5\%) compared with those in which drain was used ( 2 in 30 , $6.66 \%$ ), needing more interventions to manage these complications.

Table 2: Comparison of complications after Rhomboid excision and Limberg's rotational flap done with and without a drain

\begin{tabular}{|c|c|c|c|}
\hline Complications & With drain $(n=30)$ & Without drain $(n=8)$ & p-value \\
\hline Superficial wound infection & 2 & 5 & $\mathrm{p}<0.5$ \\
\hline Deep wound infection & - & 1 & - \\
\hline Seroma & - & 1 & - \\
\hline Haematoma & - & - & - \\
\hline Flap necrosis & - & - & - \\
\hline \multicolumn{4}{|l|}{ Additional procedures } \\
\hline Seroma drainage & - & 1 & \\
\hline Secondary suture & - & 4 & \\
\hline
\end{tabular}




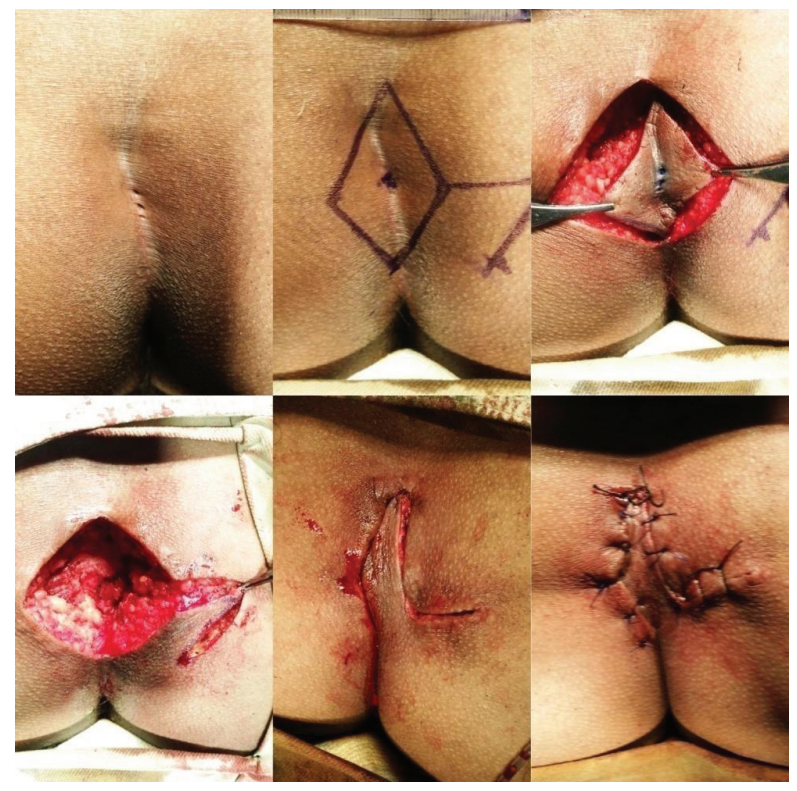

Figure 1: Steps of Rhomboid excision and Limberg rotational flap reconstruction

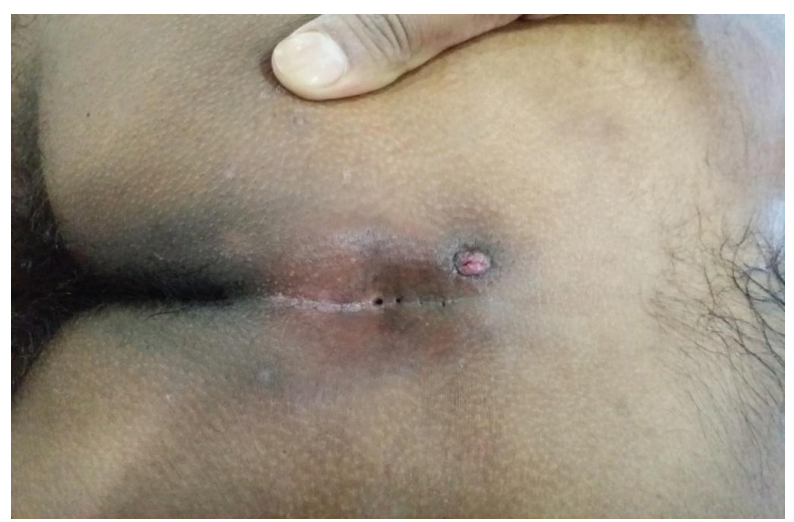

Figure 3: Pilonidal sinus with off midline accessory opening (treated with modified Limberg's flap)

\section{DISCUSSION}

Limberg flap derives its name from Professor A.A. Limberg of Leningrad, who first published about this in 1928. He later published his chapter on Limberg flap in Modern Trends in Plastic Surgery in 1963. ${ }^{1}$ It is basically a parallelogram of which all sides are equal in size with two opposite angles of 120 and 60 degrees. It is considered a versatile flap as it can be used in any part of the body and the flap can be raised from either one or from all its corners. This flap has been used for pilonidal disease successfully since the 1980s. ${ }^{2}$ The use of this flap in the sacrococcygeal region is challenging as this region is known to have more wound infections because of its poor blood supply.

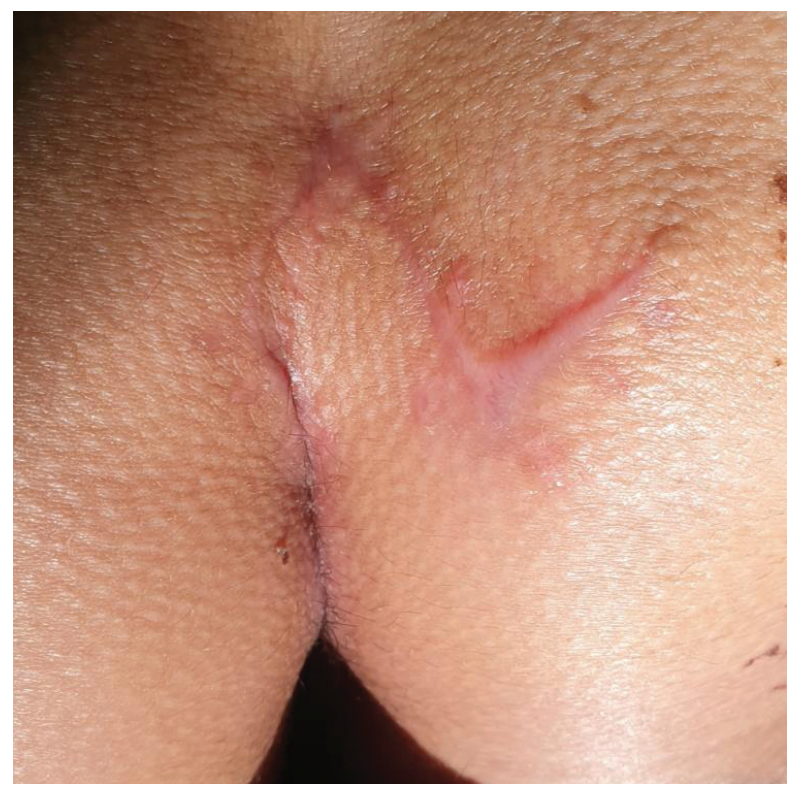

Figure 2: Condition of the wound at two weeks follow-up

In this study, a change of practice from no drain placement to routine drain placement was needed of the hour as there was an obviously unacceptable rate of complications like wound infections and seroma formation in the first eight cases (Table 2). It was deemed unethical if no intervention was done to bring down the complication rate. The easiest way is to go back to the basics of putting the drain routinely in every case. Analysis of data proved to be a beneficial intervention without much ill effect to the patient (Table 2).

The overall rate of complications varied from $4.7 \%$ to $15.9 \%$, when different methods of treatment of pilonidal sinus were undertaken. ${ }^{3}$ Complications after Limberg flap reconstruction is not uncommon which mainly consists of minor superficial wound infection to flap necrosis along with seroma, haematoma, and deep wound infections. ${ }^{4}$ In a case series of Rhomboid excision and Limberg flap, though minor wound complications like seroma, minimal necrosis of flap edge, and minor wound infection occurred in six out of 26 total patients (about 23\%). An additional procedure of secondary suture was required only in one patient (about 3\%). ${ }^{5}$ In another large series comprising 411 patients with pilonidal sinus who underwent Rhomboid excision and Limberg flap, complications like seroma and wound infection each occurred in about $3 \% .^{6}$ In both series, the drain was placed in all cases routinely. Our data of two wound infections in 30 cases (about 6\%) is lower than the smaller series but higher than the larger series. 
There is no clear data about the rate of complications when drain is not placed. Some trials showed no role of the drain in reducing wound infection. ${ }^{78}$ As shown in Table 2, superficial wound infection in five out of the total eight cases (about 62\%) and deep wound infection in one out of eight (about $12 \%$ ), which by any means is quite high. Most of the series showing successful use of this method in treating pilonidal disease has used drain.,2,5 However, one of the studies showed no difference in recurrence when the drain was placed. ${ }^{8}$

There seems to be no consensus about when to remove the drain and no studies done regarding the duration drain should be kept to reduce the infection. We routinely removed the drain on post-operative day five. Some authors have removed the drain on post-operative day two. ${ }^{2}$ Whereas, others have removed it according

\section{REFERENCES}

1. Gibson T. Modern trends in plastic surgery. London: Butterworth and Co; 1964. 319 p. [Full Text]

2. Aithal SK, Rajan CS, Reddy N. Limberg flap for sacrococcygeal pilonidal sinus a safe and sound procedure. Indian J Surg. 2013;75(4):298-301. [PubMed | Full Text | DOI]

3. Ersoy OF, Karaca S, Kayaoglu HA, Ozkan N, Celik A, Ozum T. Comparison of different surgical options in the treatment of pilonidal disease: Retrospective analysis of 175 patients. Kaohsiung J Med Sci. 2007;23:67-70. [PubMed | Full Text | DOI]

4. Jamal A, Shamim M, Hashmi F, Qureshi MI. Open excision with secondary healing versus rhomboid excision with Limberg transposition flap in the management of sacrococcygeal pilonidal disease. J Pak Med Assoc. 2009;59(3):157-60. [PubMed | Full Text] to the amount of fluid in the drain. Having drain in situ and waiting for the drain to dry up might increase the hospital stay as shown by some of the studies ${ }^{8}$ but sending the patient home along with the drain on postoperative day two or three, as practised in this study, will avoid prolonged stay in hospital.

\section{CONCLUSION}

Drain placement after Rhomboid excision and Limberg flap in the sacrococcygeal region reduces the immediate local wound complications like superficial and deep wound infection and seroma formation, thus avoiding additional procedures like secondary suturing and seroma drainage.

\section{Conflict of interest: None} Source(s) of support: None

5. Irpatgire RN, ChakrodSV.Limberg flap reconstruction following rhomboid excision of the sacrococcygeal pilonidal sinus. Int Surg J. 2016;3(2):846-9. [Full Text | DOI]

6. Akin M, Gokbayir H, Kilic K, Topgul K, Ozdemir E, FerahKose Z. Rhomboid excision and Limberg flap for managing pilonidal sinus. Long-term results in 411 patients. Colorectal Dis. 2008;10(9):945-8. [PubMed | Full Text | DOI]

7. Kirkil C, Böyük A, Bülbüller N, Aygen E, Karabulut $K$, Coşkun S. The effects of drainage on the rates of early wound complications and recurrences after Limberg flap reconstruction in patients with pilonidal disease. Tech Coloproctol. 2011;15(4):4259. [PubMed | Full Text | DOI]

8. Erdem E, Sungurtekin U, Nessar M. Are postoperative drains necessary with the Limberg flap for treatment of pilonidal sinus? Dis Colon Rectum. 1998;41(11):1427-31. [PubMed | Full Text | DOI] 